
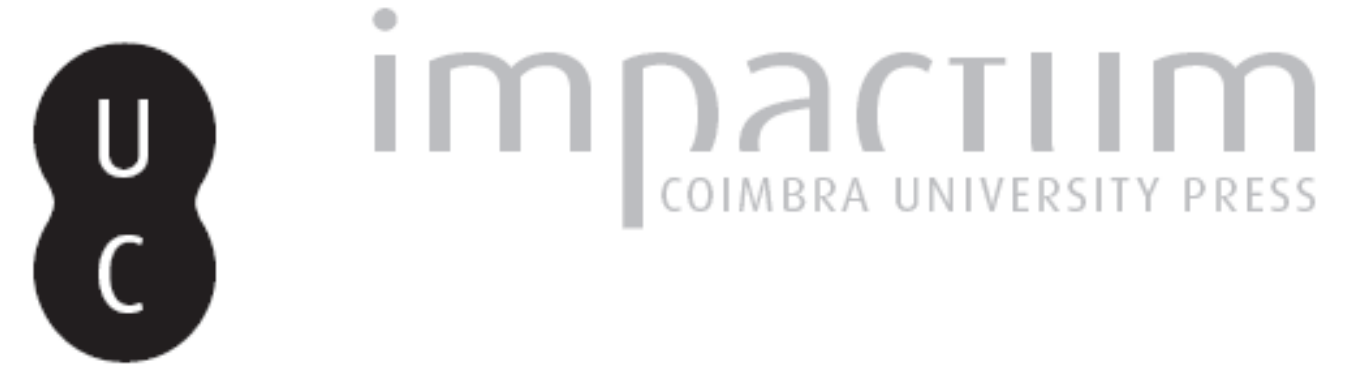

\title{
Europa em questão: comentário
}

\section{Autor(es): $\quad$ Porto, Manuel Lopes}

Publicado por: Imprensa da Universidade de Coimbra

URL persistente:

URI:http://hdl.handle.net/10316.2/36602

DOI:

DOI:http://dx.doi.org/10.14195/2183-203X_41_3

Accessed : $\quad$ 26-Apr-2023 07:23:10

A navegação consulta e descarregamento dos títulos inseridos nas Bibliotecas Digitais UC Digitalis, UC Pombalina e UC Impactum, pressupõem a aceitação plena e sem reservas dos Termos e Condições de Uso destas Bibliotecas Digitais, disponíveis em https://digitalis.uc.pt/pt-pt/termos.

Conforme exposto nos referidos Termos e Condições de Uso, o descarregamento de títulos de acesso restrito requer uma licença válida de autorização devendo o utilizador aceder ao(s) documento(s) a partir de um endereço de IP da instituição detentora da supramencionada licença.

Ao utilizador é apenas permitido o descarregamento para uso pessoal, pelo que o emprego do(s) título(s) descarregado(s) para outro fim, designadamente comercial, carece de autorização do respetivo autor ou editor da obra.

Na medida em que todas as obras da UC Digitalis se encontram protegidas pelo Código do Direito de Autor e Direitos Conexos e demais legislação aplicável, toda a cópia, parcial ou total, deste documento, nos casos em que é legalmente admitida, deverá conter ou fazer-se acompanhar por este aviso.






\section{N $\odot$ TASEC N}

YANIS VAROUFAKIS / STUART HOLLAND / JAMES K. GALBRAITH STUART HOLLAND MANUEL LOPES PORTO NUNO SILVA
A MODEST PROPOSAL FOR RESOLVING THE EUROZONE CRISIS

FALSE START FOR THE JUNCKER RECOVERY PROPOSALS EUROPA EM QUESTÃO: COMENTÁRIO

TIME-VARYING STOCK RETURN PREDICTABILITY:

THE EUROZONE CASE

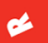

$\rightarrow$

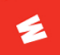

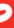

$\checkmark$

$\omega$

$\theta$

mi

-

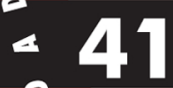
$-$

$\infty$

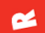
w $\Rightarrow$ $=$ $\theta$ 4

Q $\alpha$ 


\section{Europa em Questão: Comentário}

Manuel Lopes Porto
Faculdade de Direito da Universidade de Coimbra

O livro Europe in Question: And what to do about it, que acaba de ser editado (pela editora Spokesman, 2015), sendo uma reflexão sobre a Europa e o mundo é também em alguma medida uma auto-biografia do autor, dado o modo como Stuart Holland esteve envolvido em fases determinantes do processo de construção europeia.

Sendo um académico com uma formação muito aprofundada e abrangente, a leitura do livro leva-nos aliás a percorrer não só a evolução dos factos históricos como também contributos científicos que foram sendo dados ao longo dos tempos e até aos nossos dias, nos domínios da economia, da ciência política, da sociologia, da filosofia e da psicologia, entre outros.

Não obstante ter um título sobre a Europa, a "Europa em Questão", trata-se de livro em que as reflexões de Stuart Holland vão bem para além da Europa, constituem reflexões sobre o mundo em geral, o mundo em que vivemos e o mundo em que vamos viver.

Com a sua leitura, em particular com a leitura das reflexões sobre a Europa, é possível distinguir, a par de outras, seis linhas de força nas preocupações do autor, determinando em grande medida o seu pensamento e a sua acção política.

Uma primeira linha de força é a ambição de uma "Europa" em que não faltassem países que devem fazer parte dela, como é o caso do Reino Unido, durante algum tempo ausente das Comunidades. São especialmente interessantes os capítulos 3 e 4, tendo Stuart Holland condições únicas, por ter sido um participante ativo quando dos recuos e avanços do processo, para nos relatar a evolução que se foi dando: assim acontece com o relato das posições de De Gaulle ao longo do seu mandato, bem como, a par de outras, de um modo particular a posição de Harold Wilson, de quem o autor era muito próximo. Chamando em especial a atenção para as posições do então Chefe do Estado francês, dá ao capítulo 2 o título "De Gaulle Says No" e ao capítulo seguinte, sublinhando a evolução verificada, o título "De Gaulle Says Yes". Sendo depois curiosa a posição de Wilson, uma das figuras centrais em tal processo.

Uma segunda linha de força do pensamento e da acção de Holland está na afirmação da necessidade de se ter uma Europa social. Trata-se de necessidade bem afirmada no título e no conteúdo do capítulo 4, "Claiming a Social Europe", sublinhado em vários outros pontos do livro (aí, recordando que Jacques Delors foi um "key actor in seeking to set a European social agenda", antes de dedicar o capítulo seguinte, com o título "Delors, the Commission and the Council" a sublinhar o papel tão importante que teve nos mais diversos domínios). A propósito da "construção" da Europa social é especialmente interessante a descrição do processo, em que Stuart Holland foi também participante ativo, que levou à inclusão do pilar da coesão nos Tratados, começado em boa medida numa reunião, no dia 23 de Março de 1988, mencionada pelo autor (participou nela) na segunda secção do capítulo 5, secção que tem o título significativo de "The Missing Cohesion Pillar".

Trata-se de domínio, o domínio da promoção da coesão social, em que remontam a uma data muito anterior contributos académicos pioneiros de Stuart Holland, com a consideração das duas componentes, a componente regional (territorial) e a componente social em geral: sendo designadamente na primeira destas componentes uma referência já de longa data, com os livros Capital Versus the Regions e The Regional Problem (de 1978), livros com cuja leitura o autor desta nota já beneficiou quando teve especiais responsabilidades nesta área (e com pontos de vista tidos em conta designadamente numa dissertação publicada em 1982). Holland recorda aliás que "in the mid 1970s when the Maldaguer committee met, the only accepted concept of cohesion was a reduction of regional disparities" (sendo de 1975 a criação do FEDER, o Fundo Europeu de Desenvolvimento Regional). 
Uma terceira linha de força das reflexões, das propostas e do empenhamento de Stuart Holland está na necessidade de se ter um crescimento sustentado, com o financiamento que se torna indispensável para tal. São bem conhecidas as suas preocupações a tal propósito, propondo que se fuja a um austeridade excessiva, que ponha em causa um crescimento possível e desejável. Está nesta linha designadamente a referência ao tão conhecido livro de Carmen Reinhart e Kenneth Rogoff This Time is Different: Eight Centuries of Financial Folly (2009), com a defesa de que "Debt Inhibits Growth" (trata-se do título de uma secção do capítulo 8 do livro de Holland, capítulo a que significativamente dá o título de "Fatal Fictions") e referindo designadamente as dúvidas que foram levantadas acerca dos dados estatísticos desses dois economistas. $\mathrm{Na}$ mesma linha, o livro que estamos a analisar dá o relevo esperado à defesa que Stuart Holland tem vindo a fazer da emissão de "euro-bonds", referindo designadamente os apoios e as reservas que tem havido a tal propósito.

Na linha da defesa de uma estratégia de crescimento, com a maior actualidade Stuart Holland dá já relevo, no capítulo 16, com o título de "Making the Case", à "Junker Recovery Initiative" (numa secção com este título): constante do programa de candidatura de Jean-Claude Junker à presidência da Comissão Europeia, apresentado em Julho de 2014, envolvendo um montante de 300 mil milhões de euros em investimentos.

Numa quarta linha de força, no centro da investigação de Holland está também a sua preocupação no que diz respeito à "governação" (governance) das instituições europeias, com a constatação, feita no capítulo 10 (com o título "Enabling Democracy") de que "there have been persistent calls for Europe to end its democratic deficits". E é especialmente curiosa a sua referência a uma hegemonia alemã que não havia antes (durante anos teve especial relevo, no continente europeu, o eixo Paris-Bona), sublinhando que, como "previous chapters have stressed", "what emerged during the Eurozone crisis was a de facto German hegemony that earlier chancellors such as Willy Brandt and Helmut Kohl had sought to avoid".

Para o avanço do processo de "governação", ultrapassando-se resistências de alguns países a alguns propósitos, dá o relevo devido neste capítulo (numa secção sobre "Enhanced Cooperation and Economic Recovery") à necessidade de haver "cooperações reforçadas". Trata-se de afirmação na sequência e em concretização do que já tinha dito antes (p. 143), que "what is needed to close the democratic deficit are enabling decision-making procedures that can reconcile national democracy with policies that can carry the authority of the Union on jointly agreed policies and progress it without overruling national governments and overriding electorates".

Merece ainda uma referência especial neste comentário, numa quinta linha de força do seu pensamento, a afirmação feita por Holland da centralidade do "valor humano" (Human Value), num capítulo (o capítulo 14) intitulado "Efficient Economies and Efficient Societies": com a afirmação designadamente de que, face a situações não aceitáveis, o que é necessário é "to recognize that human value rather than human capital is central to both markets and society and that if market values dominate this not only will risk the destruction of society but also, with it, the principle of legitimacy on which Europe's own presumed claim to achieve the triumph of democracy has depended" (referenciando a este propósito um dos artigos que escreveu com Teresa Carla Oliveira: On the Centrality of Human Value, em Journal of Economic Methodology, vol. 19, 2012, pp. 221-241).

Como seria de esperar, num livro sobre a "Europe in Question", em que se procura saber "what to do about it", numa sexta linha de força Stuart Holland não poderia deixar de ter em conta o quadro mundial: quadro em que a Europa está obviamente integrada, como ator principal, e não podendo naturalmente um europeu deixar de ter preocupação com o que se passa e de procurar caminhos de esperança realista para os cidadãos dos demais espaços do mundo, em especial para os cidadãos das áreas mais desfavorecidas.

Assim acontece já no capítulo 9, intitulado "The Great Regression", em que, a par de outras referências, dá um relevo especial ao recente livro de Thomas Piketty Capital in the Twenty-First 
Century (2013/14): em que é designadamente feita a afirmação da crescente maior concentração de riqueza no capital, contrariando afirmações, de Simon Kusnets e vários outros autores, no sentido de que "income disparities had been reduced by economic growth from the end of World War Two, and would continue to do so". Na opinião de Holland, "Piketty understates key factors which enabled the 'Keynesian era' and which had more to do with transformation of the structure of supply than with Keynes'case for demand management”.

$\mathrm{Na}$ análise dos desequilíbrios no plano internacional, numa posição que poderá discutir-se, Holland põe em causa o entendimento de Piketty no sentido de que "foreign investment had little role in the emergency of the newly industralising economies of Asia such as South Korea, Taiwan and China" e de que "they have benefited far more from open markets for goods and services and advantageous terms of trade than from capital flows". No seu livro, Holland dá um relevo maior aos fluxos de capitais, sendo interessante designadamente a referência aos números de uma conhecida consultora, com a afirmação de que "by the beginning of the 21st century half of the exports from China to the rest of the world were from foreign direct investment", bem como a referência, numa secção do capítulo 12 com o título "Foreign Investment Drives Globalisation", de que "from World War II it was less comparative advantage than the FDI of foreign Direct investment that drove globalisation".

Havendo de todo o modo problemas delicadíssimos a resolver, designadamente em áreas mais desfavorecidas do mundo, justificam-se bem os contributos de Stuart Holland no sentido da sua resolução, apontando em particular para que haja um adequado quadro regulatório mundial, capaz de responder aos desafios atuais e que se avizinham. Trata-se de quadro considerado no capítulo 17, com o título "Europe, the G20 and Global Governance", em que começa por recordar que "before the first meeting of the G20 heads of state and government in Washington in 2008 there were calls for a New Bretton Woods", lamentando que todavia não se tenha verificado consenso a tal propósito. Recorda depois a versão pessimista do Clube de Rome, em 1972 (apontando para a inevitabilidade de se ter um crescimento $0 . .$. ) e avança no sentido de se seguirem caminhos de progresso. E depois de uma referência especial ao papel dos BRICS, numa secção com a designação de "The BRICS Strike Back" (depois de a China ter sido já largamente considerada, em especial em duas secções do capítulo 12, uma delas com o título "Challenge from China", e a outra com o título "Challenge for China"...), numa secção seguinte aponta, a par do fortalecimento de outras instituições, para necessidade de uma "World Development Organization", com contornos que procura identificar; depois de numa secção anterior ter sublinhado que onde "both Keynes and the first generation Keynesians nonetheless were right was in not assuming that comparative advantage alone would maximize global welfare unless there already was full employment".

Terá resultado das referências e reflexões que fomos fazendo que temos perante nós um livro com várias posições que não são consensuais. Não poderia aliás deixar de ser assim, estando em causa pontos em que não há um acordo generalizado entre os académicos e os responsáveis políticos do mundo.

Mas o mérito do livro é acrescido precisamente por proporcionar elementos com o maior valor para as discussões que necessariamente tem de haver: discussões que ficam enriquecidas com os contributos que Stuart Holland nos dá, partilhando o seu saber e a sua experiência.

Estamos seguros, aliás, de que o autor se sentirá especialmente feliz por alimentar deste modo um debate fecundo que importa que continue a ter lugar, enriquecendo o meio académico e contribuindo para que os decisores políticos sigam os caminhos mais adequados. 